\section{Amino acid sequences mediating vascular cell adhesion molecule 1 binding to integrin alpha 4: homologous DSP sequence found for JC polyoma VP1 coat protein}

\author{
Michael Andrew Meyer \\ Department of Neurology, Tennova \\ Health Care, Knoxville, TN, USA
}

\section{Abstract}

The JC polyoma viral coat protein VP1 was analyzed for amino acid sequences homologies to the IDSP sequence which mediates binding of VLA-4 (integrin alpha 4) to vascular cell adhesion molecule 1. Although the full sequence was not found, a DSP sequence was located near the critical arginine residue linked to infectivity of the virus and binding to sialic acid containing molecules such as integrins (3). For the JC polyoma virus, a DSP sequence was found at residues 70,71 and 72 with homology also noted for the mouse polyoma virus and SV40 virus. Three dimensional modeling of the VP1 molecule suggests that the DSP loop has an accessible site for interaction from the external side of the assembled viral capsid pentamer.

\section{Introduction}

Administration of an antibody (natalizumab) to the alpha 4 integrin molecule binding site to the head region of the vascular cell adhesion molecule 1 (VCAM-1) molecule was found to be associated with systemic JC viremia and subsequent progressive multifocal leukoencephalopathy (PML) in a 60 year old Crohn's disease patient who had been previously treated with infliximab and azothioprine. ${ }^{1}$ After only 6 administrations of the natalizumab antibody, serum JC viral load rose from being undetectable to 520 copies/mL and then to 6600 DNA copies/mL two months later when PML was suspected, and required brain biopsy for diagnosis; up to 3.9 million JC virus DNA copies per brain glial cell were found.

Since the exact cause of the JC viremia remains unclear in this case, the future therapeutic role for natalizumab in treating multiple sclerosis and other disorders remains uncertain. To help understand the pathogenesis of antibody related JC viremia and subsequent PML, it is hypothesized here that the alpha 4 integrin antibody may disrupt the peripheral binding of the virus in natural tissue reservoirs in certain individuals; JC viremia after blockade of the normal alpha 4 integrin binding sites for the virus in lymphoid tissue such as spleen and the tonsils could overwhelm the normal cytotoxic $\mathrm{T}$ cell immune surveillance defense mechanisms. Indirect support for this hypothesis of peripheral binding of VP1 to alpha 4 integrin in lymphoid tissue comes from the work of Caruso et al. . $^{2,3}$ who found an important VP1 receptor function for the alpha 4 integrin molecule, which like the beta 1 integrin molecule is heavily glycosylated with terminal sialic acid residues, ${ }^{4}$ which were already known to mediate VP1 attachment. This study therefore attempts to identify critical amino acid binding sequences that may mediate an interaction between alpha 4 integrin molecules in normal host tissue and the $\mathrm{JC}$ virus VP1 coat proteins. Since IDSP is a critical VCAM-1 amino acid sequence for binding to the alpha 4 integrin, 5 a search was made to find a similar sequence in the VP1 protein that could mediate an attachment to integrins.

\section{Materials and Methods}

Using accession number J02288.1, the protein sequence for the polyoma VP1 coat protein was analyzed for IDSP sequences using the National Center for Biotechnology Information on-line data base (on-line web address: http://www.ncbi.nlm.nih.gov/). Enumeration of the amino acid residues followed the convention of numbering VP1 residues after the initial Met residue (Caruso et al. ${ }^{3}$ ). Alignment information for different strains of polyoma virus was analyzed by a conserved domain search at the following on-line web address: http://www.ncbi.nlm.nih.gov/Structure/cdd/wrp sb.cgi. 6

The localization of the DSP sequence for the human polyoma VP1 protein was studied using the Molecular Modeling Database (MMDB), which enables reconstruction and interactive viewing of the three dimensional macromolecular structures with Cn3D software; web address: http:/www.ncbi.nlm.nih.gov/entrez/query.fcgi?d $\mathrm{b}=$ Structure

The individual VP1 protein structure was analyzed as well as one of the 72 pentameric icosahedral capsids that cover the surface of the polyoma virus, and visualized in relation to hydrophobicity as well as charge.

\section{Findings}

Although the full IDSP sequence was not found, a DSP sequence was found for the JC polyoma virus VP1 coat protein (accession number P03089) as well as Mouse polyomavirus (strain p16 small-plaque; accession-
Correspondence: Michael Andrew Meyer Department of Neurology, Tennova Health Care, Knoxville, 930 Emerald Avenue, Suite 511, Knoxville, TN 37917, USA.

Tel. +1.865.647-3330

E-mail: michaelandrewmeyer@gmail.com

Key words: JC, polyoma, virus, VP1, capsid, alpha 4 integrin, PML.

Acknowledgments: the author wishes to thank Mrs. Eunice Soper and the Soper Neuroscience Fund for encouragement and support for this study; the author also thanks Dr. William T. Ruyechan from the Univ. Buffalo Dept Microbiology \& Immunology for reviewing an initial version of this manuscript.

Conflict of interests: the author declares no potential conflict of interests.

Received for publication: 5 May 2013. Accepted for publication: 10 July 2013.

This work is licensed under a Creative Commons Attribution NonCommercial 3.0 License (CC BYNC 3.0).

(C) Copyright M.A. Meyer, 2013

Licensee PAGEPress, Italy

Neurology International 2013; 5:e14

doi:10.4081/ni.2013.e14

number 1SIE_A), as well as Chain 1, Simian Virus 40 (accession number 1SVA_1), but not for Kilham polyomavirus (accession number P24595), Budgerigar fledgling polyomavirus (BFPyV; accession number P13891), Hamster polyomavirus (HaPyV; accession number P03092), African green monkey polyomavirus (accession number P04010), or Bovine polyomavirus (accession number P24848). Alligned short segments of VP1 which display the homologous DSP sequence are shown in red in Figure 1 with residues 70,71, and 72 for the JC polyoma virus being aspartic acid (D), serine $(\mathrm{S})$, and proline $(\mathrm{P})$ respectively. The three dimensional external view of a single pentamer capsid (Figure 2) reveals accessible DSP residues for interaction and potential ligand binding. A detailed interactive review of a ball and stick type model (Figure 3 ) one of the five individual molecules that form a pentamer suggests a peripheral location to the DSP loop in relation to the bulk of the VP1 molecule, with the suggestion that a pocket is formed by this eccentric peripheral loop that could allow insertion of a small ligand molecule into this site.

\section{Discussion}

As reported in preliminary form by Meyer, ${ }^{7}$ a DSP sequence has now been found that may 
represent a alpha 4 integrin binding site for the major JC polyoma virus external coat protein known as VP1. Since the IDSP sequence is critical in binding VCAM-1 to the alpha 4 integrin molecule, and since the alpha 4 integrin molecule is also thought to serve as a postattachment receptor for $\mathrm{VP} 1,2$ it is possible that that antibodies to the alpha 4 integrin molecule leaves the virus in peripheral lymphoid tissue in a free and unbound state. Since the alpha 4 integrin antibody natalizumab is associated with JC viremia and subsequent overwhelming brain infection by the virus (PML), it is hypothesized that alpha 4 integrin molecules in lymphoid tissue normally binds to the JC virus VP1 protein to render it non-infective by successfully competing with other receptors for the virus. The binding may be mediated by the DSP motif at residues 70,71, and 72 for JC, and at $88,89,90$ for the murine polyoma $\mathrm{A} 2$ strain; for the latter, a nearby critical Arginine residue at position 77 governs infectivity of the virus and is believed to bind to sialic acid containing molecules such as integrins. ${ }^{3}$ It is unclear if DSP mediated binding of VP1 to the alpa 4 integrin integrin molecule produces secondary conformational changes at the nearby VP1 Arginine 77 sialic acid binding site to alter infectivity of the virus.

Extensive literature exists regarding other viruses that display specific binding to integrins; antibodies to specific integrins can prevent infection by specific cytopathic viruses that normally do not show the JC phenomenon of long term benign persistence and dormancy within tissue. The alpha 6 integrin likely serves as a cellular receptor for papillomaviruses, ${ }^{8}$ whereas the alpha 5 beta 6 integrin binds to cocksackie virus A9 through a RGD amino acid sequence; ${ }^{9}$ this sequence is also implicated in the binding of B cell lymphotropic polyoma virus capsids to the alphav beta 3 integrin. ${ }^{10}$ When the alphav is found in combination with beta 8 , this integrin can serve as a receptor for the foot and mouth disease virus; 11 when alphav combines with beta 1 , the integrin molecule dimer can be a receptor for the adenovirus. ${ }^{12}$ The alphav integrin is particularly important, as other combinations yield different viral specificities: when combined with beta 3 , the integrin dimer can bind the West Nile virus, ${ }^{13}$ cytomegalovirus, ${ }^{14}$ as well as Rotavirus. ${ }^{15}$ Regarding the Kaposi's sarcoma-associated herpesvirus, viral entry is mediated by binding to the alpha3betal integrin. ${ }^{16}$ Beta 3 integrin has been found to serve a receptor function for the Hantavirus. ${ }^{17}$ Infectivity seems to depend on binding to inactive, bent, alphavbeta3-integrin molecules at a specific bend site at the plexin-semaphorinintegrin (PSI), 18 where molecular motion could otherwise take place to straighten the molecule into an active form.

Further research is needed to understand if

YYGWSRGINLATSDTEDSPGNNTLPTWSMAKLQLPMLNEDLT 113 QKGLSKSLAAEKQFTDDSPDKEQLPCYSVARI PLPNINEDLT 103 FYGFSDNITVSADYTQDMPRIKELPCYSMAKISLPMLNEDMT 101 KNGYSTVITVQAEGYQDAPHSTEVPCYSCARIPLPTINDDIT 91 YYGFSQSIKVNSSLTADEVKANQLPYYSMAKIQLPTLNEDLT 101 LYGYSNSINTAFSKASDTPNKDTLPCYSVAVIKLPLLNEDMT 104 YYGFSDNQRGSTSRTDEDLISAELPRYSLGVVQLPLLNEKLT 103 LRGFSKSISISDTFESDSPNRDMLPCYSVARIPLPNLNEDLT 96

Figure 1. The sequence allignment (red displaying the DSP sequence) shows portions of the initial segment of amino acids for the following VP1 coat protein for polyoma viruses, in descending order from top down: Mouse polyomavirus (strain p16 small-plaque), Simian virus 40, Kilham polyomavirus, Budgerigar fledgling disease, polyomavirus (BFPyV), Hamster polyomavirus ( $\mathrm{HaPyV})$, African green monkey polyomavirus, Bovine polyomavirus, JC polyomavirus.

alpha 4 integrin binding to the DSP sequence of VP1 normally leaves the JC virus in a noninfective state. Successful competition with other tissue receptors for the virus might be an adequate explanation for why the JC virus can found in normal tissue of over $70 \%$ of normal individuals without causing PML, ${ }^{19}$ which is extremely rare in fully immunocompetent individuals, yet linked to PML in up to 4 to $6 \%$ of immunosuppressed HIV infected patients. In vitro studies are needed as well to test if synthetic DSP sequences can inhibit binding of VP1 to alpha 4 integrin molecules; should such an interaction be documented, it may have relevance to the understanding the natural biology of the JC polyoma virus, which can remain non-infective in not only kidney and lymphoid tissue, but also even the brain. ${ }^{19}$ Further understanding of how the JC virus persists is important in understanding multiple disease states, including primary brain tumors, which have been found to harbor the virus and express $\mathrm{T}$ antigens in oligodendrogliomas. ${ }^{20}$

This study has limitations in that the key publications by Caruso et al.2,3 which found a viral VP1 protein receptor function for the alpha 4 integrin molecule, derived their research findings from the murine polyoma virus; however, like the beta 1 integrin molecule and the serotonin receptor molecule, the alpha 4 integrin molecule is heavily glycosylated with terminal sialic acid residues. It is important to also note that blockade of the serotonin receptor $2 \mathrm{~A}$ by risperidone does not inhibit JCV attachment, internalization and replication in primary human fetal glial cells, ${ }^{21}$ raising questions about the biologic relevance about data concerning the serotonin receptor also serving as a proposed receptor for the JC virus in light of the well established role for integrin molecules as receptors for other viruses; furthermore, linear sialylated pentasaccharides with the sequence NeuNAc- $\alpha 2,6$-Gal$\beta 1,4$-GlcNAc- $\beta 1,3-$ Gal- $\beta 1,4-G l c$ present on host

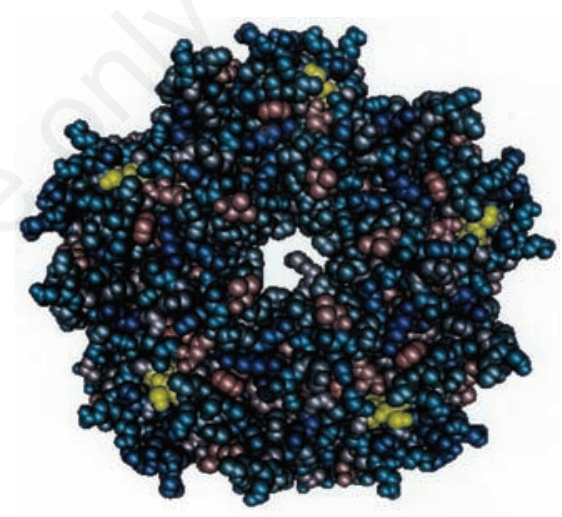

Figure 2. A view of the external face of a pentameric capsid of VP1 proteins (one of 72 capsids comprising the JC polyoma virus); the DSP sequence is seen in yellow for each of the five VP1 subunits.

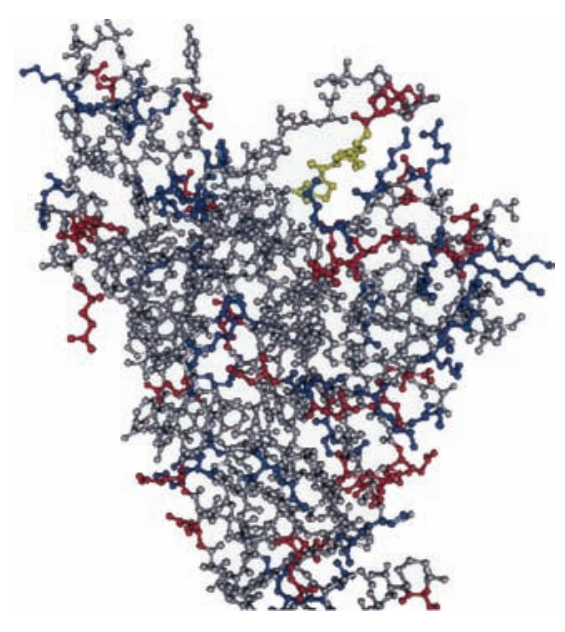

Figure 3. The VP1 protein as a ball and stick representation colored according to charge, with yellow indicating the DSP sequence homologous to the IDSP sequence mediating VCAM-1 binding to the alpha 4 integrin molecule. 
glycoproteins and glycolipids have now been found to serve as a specific JCV recognition motif - future research is needed to understand how this applies to integrin alpha 4 terminal oligosaccharide sequences. ${ }^{22}$

Finally, it is important to point out that caution with the use of Natalizumab is strongly advised, as the latest data has revealed an incidence rate of 212 confirmed cases of PML among 99,571 patients treated with Natalizumab, equating to 2.1 cases per 1000 treated patients. ${ }^{23}$

\section{References}

1. Van Assche G, Van Ranst M, Sciot R, et al. Progressive multifocal leukoencephalopathy after Natalizumab therapy for Crohn's Disease. N Engl J Med 2005;353:362-8.

2. Caruso M, Belloni L, Sthandier 0, et al. Alpha4betal integrin acts as a cell receptor for murine polyomavirus at the postattachment level. J Virol 2003;77:3913-21.

3. Caruso M, Cavaldesi M, Gentile M, et al. Role of sialic acid-containing molecules and the alpha4betal integrin receptor in the early steps of polyomavirus infection. $\mathrm{J}$ Gen Virol 2003;84:2927-36.

4. Hemler, ME, Jacobson, JG, Strominger, JL Biochemical characterization of VLA-1 and VLA-2. Cell surface heterodimers on activated T cells. J Biol Chem 1985;260:15246-52.

5. Clements JM, Newham P, Shepherd M, et al. Identification of a key integrin-binding sequence in VCAM-1 homologous to the LDV active site in fibronectin. J Cell Sci 1994;107:2127-35.
6. Marchler-Bauer A, Bryant SH. CD-Search: protein domain annotations on the fly Nucleic Acids Res 2004;32:W327-31.

7. Meyer MA. VCAM-1 related DSP binding motif detected within JC viral coat protein VP1: possible relationship to the integrin alpha 4 protein. J Neurovirol 2005;11 [Abstract]

8. Evander M, Frazer IH, Payne E, et al. Identification of the alpha6 integrin as a candidate receptor for papillomaviruses. J Virol 1997;71:2449-56.

9. Williams CH, Kajander T, Hyypia T, et.al. Integrin alpha v beta 6 is an RGD-dependent receptor for coxsackievirus A9. J Virol 2004;78:6967-73.

10. Langner J, Neumann B, Goodman SL, Pawlita M. RGD-mutants of B-lymphotropic polyomavirus capsids specifically bind to alpha(v)beta3 integrin. Arch Virol 2004; 149:1877-96.

11. Jackson T, Clark S, Berryman S. Integrin alphavbeta8 functions as a receptor for foot-and-mouth disease virus: role of the beta-chain cytodomain in integrin-mediated infection. J Virol 2004;78:4533-40.

12. Li E, Brown SL, Stupack DG, et.al. Integrin alpha(v)betal is an Adenovirus Coreceptor. J Virol 2001;75:5405-9.

13. Chu JJ, Ng ML. Interaction of West Nile virus with alpha v beta 3 integrin mediates virus entry into cells. Biol Chem 2004;279:54533-41.

14. Wang X, Huang DY, Huong SM, Huang ES. Integrin alphavbeta3 is a coreceptor for human cytomegalovirus. Nat Med 2005;11: 515-21.

15. Guerrero CA, Mendez E, Zarate S. Integrin alpha(v)beta(3) mediates rotaviruscell entry. Proc Natl Acad Sci USA 2000;97:
14644-9.

16. Akula SM, Pramod NP, Wang FZ, Chandran B. Integrin alpha3betal (CD 49c/29) is a cellular receptor for Kaposi's sarcomaassociated herpesvirus (KSHV/HHV-8) entry into the target cells. Cell 2002;108: 407-19.

17. Song JW, Song KJ, Baek LJ, et al. In vivo characterization of the integrin beta3 as a receptor for Hantaan virus cellular entry. Exp Mol Med 2005;37:121-7.

18. Raymond T, Gorbunova E, Gavrilovskaya IN, Mackow ER. Pathogenic hantaviruses bind plexin-semaphorin-integrin domains present at the apex of inactive, bent alphavbeta3 integrin conformers. Proc Natl Acad Sci USA 2005;102:1163-8.

19. White FA, Ishaq M, Stoner GL, Frisque RJ. $\mathrm{JC}$ virus DNA is present in many human brain samples from patients without progressive multifocal leukoencephalopathy. J Virol 1992;66:5726-34.

20. Del Valle L, Enam S, Lara C, et al. Detection of JC polyomavirus DNA sequences and cellular localization of T-antigen and agnoprotein in oligodendrogliomas. Clin Cancer Res 2002;8:3332-40.

21. Chapagain ML, Sumibcay L, Gurjav U, et al. Serotonin recepto $2 \mathrm{~A}$ blocker (risperidone) has no effect on human polyomavirus JC infection of primary human fetal glial cells. J Neurovirol 2008;14:448-54.

22. Neu U, Maginnis MS, Palma AS, et al. Structure-function analysis of the human JC polyomavirus establishes the LSTc pentasaccharide as a functional receptor motif. Cell Host Microbe 2010;8:309-19.

23. Bloomgren G, Richman S, Hotermans C, et al. Risk of natalizumab-associated progressive multifocal leukoencephalopathy. 